Jurnal JINTEKS Vol. 1 No. 1 Agustus 2019

\title{
RANCANG BANGUN APLIKASI HYBRID PENJUALAN KULINER DI PANTAI JEMPOL SUMBAWA
}

\author{
Mukliani $^{1}$, Yudi Mulyanto ${ }^{2}$, Yana Karisma ${ }^{3}$ \\ 1.2 Program Studi Informatika, Fakultas Teknik, Universitas Teknologi Sumbawa \\ $1.2 \mathrm{Jl}$. Raya Olat Maras Batu Alang-Sumbawa Besar \\ 1mukliai1997@gmail.com, ${ }^{2}$ yudi.mulyato@uts.ac.id, ${ }^{3}$ yana.karisma@uts.ac.id
}

\begin{abstract}
Abstrak
Penjualan merupakan aset usaha yang terpadu dalam mengembangkan rencana-rencana strategis yang diarahkan pada usaha pemuasan kebutuhan serta keinginan pembeli, guna mendapatkan penjualan yang menghasilkan laba. Pantai Jempol Sumbawa merupakan salah satu contoh tempat yang memiliki sekumpulan usaha pedagangan khususnya pada usaha bidang kuliner yang dapat di kembangkan. Dalam hal inimaka untuk itu penulis bertujuan merancang dan membangun sebuah aplikasi hybrid penjualan dan pemasaran yang informasinya akurat relevan dan tepat waktu yakni yang berjudul Aplikasi Hybrid Pejualan Kuliner di Pantai Jempol Sumbawa. Dalam penelitian ini metode yang digunakanialah metode waterfall. Adapun tujuan dari penelitian ini ialah untuk membuat sistem manual yang sedang berjalan pada pantai Jempol (Jembatan Polak) menjadi sistem yang terkomputerisasi, sehingga dapat dibangun aplikasi tersebut. Aplikasi ini mempermudah admin, penjual, customer maupun masyarakat dalam melakukan proses penjualan serta mendapat informasi tentang penjualan kuliner dipantai jempol sumbawa.
\end{abstract}

Kata Kunci : Aplikasi, Hybrid, Penjualan, Kuliner,Watefall.

\begin{abstract}
Sales are integrated business assets in developing strategic plans that are directed at efforts to satisfy the needs and desires of buyers, in order to get profit-generating sales. Pantai Jempol Sumbawa is one example of a place that has a collection of trade businesses, especially in the culinary field that can be developed. In this case, the writer aims to design and build a hybrid sales and marketing application with accurate and relevant information. The method is the waterfall. The purpose of this study is to make a manual system that is running on the Pantai Jempol (Jembatan Polak) into a computerized system, so that the application can be built. This application makes it easy for administrators, sellers, customers and the public to carry out the sales process and get information about culinary sales on the Sumbawa thumb beach.
\end{abstract}

Keywords: Applications, Hybrid, Sales, Culinary, Watefall.

\section{PENDAHULUAN}

Kuliner merupakan sebuah jenis wisata yang sangat marak saat ini dan memberi sumbangsih besar pada perkembangan kuliner disumbawa, bukan hanya beragam makanan nasional namun juga mengangkat aneka makanan asli daerah yang saat ini sudah mulai tergeser oleh macam-macam produk asing ataupun berorentasi makanan asing. Untuk itu perlu adanya dibuat sebuah usaha untuk meningkatkan potensi ekonomis ini dengan memberikan sentuhan atau dukungan untuk dapat menarik wisatawan lokal atau asing dalam menikmati kuliner asli daerah.Sumbawa
Besar adalah ibukota Kabupaten Sumbawa, Provinsi Nusa Tenggara Barat, yang berada di Pulau Sumbawa atau biasa dijuluki dengan semboyan "Sabalong Samalewa", Sumbawa sangat kaya akan wisata dan kulinernya khususnya yang terletak di PantaiJempol (Jembatan Polak), menyediakan kuliner khas sumbawa yang bisa dinikmati. Ada banyak pantai yang berada dipulau Sumbawa namun pantai Jempol memiliki daya tarik tersendiri dibandingkan dengan pantai lainnya. Sehingga banyak masyarakat yang berkunjung untuk menikmati kuliner khas sumbawa yang ada dipantai Jempol. Akan tetapi perlu adanya 
peningkatan untuk memajukan perkembangan baik dari segi lokasi maupun dari kuliner yang ada dipantai jempol. Karena sebagian masyarakat sumbawa masih ada yang belum megetahuinya.

Oleh karena itu penulis akan merancang sebuahaplikasihybrid penjualan kuliner guna untuk membantu masyarakat sumbawa agar lebih mudah dalam mengetahui kuliner apa saja yang ada dipantai jempol baik dalam pengetahuan tempat maupun dalam melakukan proses pejualan dan pemesanan makanan.

\section{TINJAUAN PUSTAKA}

Penelitian yang dilakukan oleh Pandayin (2012), membuat sebuah aplikas iyaitu "Situs pada Aplikasi Katalog Wisata Kuliner berbasis Web" dibuat dengan menerapkan metode User Centered Design (UCD) adalah untuk mempermudah penggunaan dalam fasilitas yang ada dalam website tersebut ketika mencari informasi mengenai kuliner di Yogyakarta. Persamaan yang dimilki dengan aplikasi penulis buat yakni adalah sama - sama bertujuan membangun aplikasi yang efektif dan efisienSedangkan perbedaan yang di miliki dalam aplikasi tersebut ialah aplikasi ini menggunakan metode kualitatif.

Pada penelitian Agasa, (2012), terdahulu yang berjudul "Peta Rekomendasi Pariwisata dan Kuliner Kabupaten Semarang dengan Metode Pencarian Terdekat Dijkstra" bertujuan untuk mempermudah wisatawan asing maupun local dalam merencanakan rute pariwisata maupun lokasi kuliner yang terdekat dari tujuan mereka. Sistem ini dalam pencarian rute terdekat user menentukan lokasi awal dan tujuan secara manual. Informasi yang ditampilkan hanya jalur terdekat untuk menuju kedaerah tujuan dan tidak menampilkan informasi lainnya yang menunjang dar ilokasi pariwisata maupun lokasi kuliner. Fitur yang ditawarkan pada system informasi ini masih sangat kurang. Sedangkan aplikasi yang di buat peneliti ialah aplikasi yang berjalan di system operasi berbasis web, bisa juga berjalan diandroid kerena berjenis hybrid untuk mempermudah sebagai media promosi penjualan kuliner serta terdapat juga proses pemesanannya.

Setelah membandingkan dari beberapa penelitian yang telah dilakukan di atas maka penulis melakukanpenelitian yang berfokus Pada Rancang BangunAplikasi Hybrid Penjualan Kuliner Di Pantai
Jempol Sumbawa. Untuk mengganti sistem yang manual dengan judul "AplikasiHybrid Penjualan Kuliner Di Pantai Jempol Sumbawa". Dengan metode pengembangan sistem yang digunakan adalah metode waterfall.. Dengan fitur yang akan ditampilkan dalam sistem diantaranya yaitu data customer, data produk, data pesanan dan pembayaran.

\subsection{Penjualan}

Penulis memaparkan definisi Penjualan menurut Wahana dan Riswaya (2014: 29), bahwa Penjualan adalah salah satu aktivitas operasi dari koperasi, selain itu penjualan juga merupakan salah satu tujuan utama dari koperasi karena merupakan bagian yang penting, baik untuk perusahaan industri, perusahaan perdagangan maupun koperasi.

Definisi lain penjualan menurut Aryanto dan Tjendrowasono (2012: 57), bahwa penjualan atau e-commersmerupakan salah satu teknologi yang berkembang sangat pesat pembelian dan penjualanbarang dan jasa melalui jaringan atau media elektronik.

Jadi dapat ditarik kesimpulan bahwa penjualan merupakan suatu proses dalam mendapatkkan laba baik dalam perusahaan maupun koperasi yang berupa barang dan jasa kemudian di kembangkan melalui jaringan elektronik.

\subsection{Web}

Web merupakan sebuah teknologi sistem informasi yang menghubungkan data dari banyak sumber dan layanan yang beragam macamnya di internet, Web cepat sekali populer di lingkungan pengguna internet, karena kemudahan yang diberikan kepada pengguna internet untuk melakukan penelusuran, penjelajahan, danpencarian informasi.

Menurut Abbas (2013: 2), bahwa Website disebut juga site, situs, situs web atau portal kumpulan halaman web yang berhubungan antara satu dengan lainnya, yakni halaman pertama sebuah website adalah home page, sedangkan halaman demi halamannya secara mandiri disebut web page, situs yang dapat diakses dan dilihat oleh para pengguna internet diseluruh dunia dan dilihat oleh para pengguna Internet yang semakin hari semakin bertambah banyak, sehingga hal ini adalah potensi pasar yang berkembang terus.

\subsection{UML(Unified Modeling Language)}

Penulis memaparkan definisi UML (Unified Modeling Language) menurut Aditya dan 
Iskandar (2015: 1825) dalam jurnalmya dijelaskan bahwa UML (Unified Modeling Language) merupakan sebuah notasi grafis, yang di dukung oleh metode tunggal, yang dapat membantu dalam menggambarkan dan merancang sistem perangkat lunak, khususnya pada sistem perangkat lunak yang dibangun dengan model berorientasi objek.

Adapun definisi lain Unified Modelling Language (UML) menurut Mallu (2015: 38), bahwa Unified Modelling Language (UML) adalah sebuah "bahasa" yang telah menjadi standarisasi dalam industri untuk visualisasi, merancang dan mendokumentasikan sistem piranti lunak. UML yang menawarkan sebuah standar untuk merancang model sebuah system atau notasi merupakan sekumpulan bentuk khusus untuk menggambarkan berbagai diagram piranti lunak.

\subsection{Android}

Penulis memaparkan definisi Android menurut Pamungkas dan Yuliansyah (2017: 28), merupakan sebuah sistem operasi perangkat mobile berbasis linux yang mencakup sistem operasi, middleware, dan apliakasi. sehingga pengembang dapat dengan bebas membuat aplikasi android karena merupakan platform terbuka (Open Source).

Adapun definisi lain menurut Syahputri dan Mansur (2018), Android merupakan sistem operasi yang dikembangkan untuk perangkat mobile berbasis Linux. Android yang menyediakan sebuah platform terbuka bagi para pengembang untuk menciptakan aplikasi mereka sendiri untuk dapat digunakan oleh bermacammacam peranti bergerak.

Jadi kesimpulan dari penulis bahwa android merupakan sarana aplikasi OS mobile yang berinteraksi menggunakan OS Linux sehingga aplikasi yang kita buat dapat berjalan dengan baik, baik itu berupa telpon seluler atau layar sentuh (touchscreen).

\subsection{Waterfall}

Definisi Waterfall menurut Mafaza dan Rochmawati (2019: 29), bahwa waterfall sering disebut metode air terjun atau sering juga dinamakan siklus hidup klasik (classic life cycle), hal ini menggambarkan sebuah pendekatan yang sistematis dan juga berurutan pada pengembangan perangkat lunak, dimulai dari spesifikasi kebutuhan pengguna kemudian memulai tahapan - tahapan perancangan, permodelan, konstruksi, serta penyerahan sistem ke pengguna (deployment) dan tahap terakhir dengan dukungan perangkat lunaklengkap yang dihasilkan.

Adapun penjelasan lain menurut Ihsanuddin, dkk (2016: 57), bahwa Waterfallmerupakanmodel yangmemberikan pendekatan-pendekatan sistematis dan berurutan bagi pengembangan sebuah piranti lunak.

\section{METODE PENELITIAN}

\subsection{Alur Penelitian}

Dalam penelitian ini terdapat beberapa tahapan yang dilakukan oleh peneliti yang digambarkan dalam alur penelitian berikut.

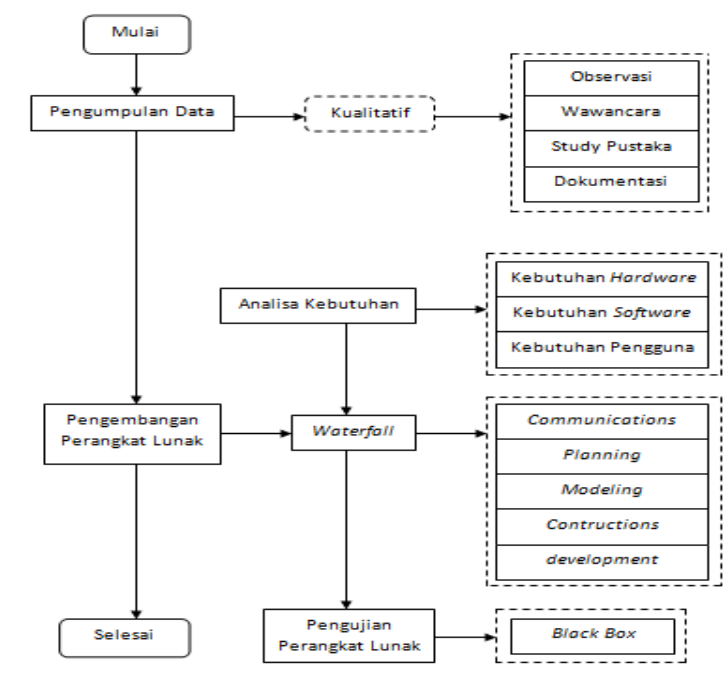

Gambar 3.1 Alur Penelitian

Pada Gambar 3.1 di atas menggambarkan alur penelitian yang dimulai dari pengumpulan data menggunakan metode penelitian kualitatif yang terdiri dari teknik observasi, teknik wawancara dan teknik studi pustaka.Kemudian memulai tahapan penelitian menggunakan metode pengembangan perangkat lunak waterfall yang terdiri dari tahap analisis,perencanaan, desain, pengkodean, implementasi dan pengujian.

\subsection{Metode Pengumpulan Data}

Metode pengumpulan data yang digunakan oleh peneliti untuk mendapatkan informasi yang dibutuhkan saat penelitian adalah dengan beberapa metodeseperti:

a) Observasi

Sebagai objek penelitian dalam penerapan sistem informasi pengolahan data akademik berbasis web, penelitian ini melakukan observasi pada Wisata Kuliner Pantai Jempol Sumbawa. Observasi 
dilakukan untuk mengetahui cara kerja aktivitas penjualan yang ada padaWisata Kuliner Pantai Jempol tersebut, sehingga dapat dilakukan analisis untuk mengetahui kebutuhan apa saja yang digunakan dalam membangun sistem penjualan serta melakukan pengamatan secara lansung pada objek penyampaian informasi penjualan dipantai jempol.

b) Wawancara

Melakukan tanya jawab tanpa adanya perantara atau tatap muka secara lansung kepada narasumber dalam melakukan peneitian. Pada saat melakukan observasi peneliti melakukan wawancara kepada para pedagang yang berjualan dipantai tersebut serta .Sedikit membahas tentang prosespenjualan dan datadata yang dibutuhakan dalam proses pernjualan.

c) Studi Pustaka

Studi pustaka adalah memepelajari referensi lain yang berkaitan dengan masalah yang akan dibahas atau melakukan studi terhadap litelatur (buku-buku) tentang objek yang akan dibahas untuk dapat dijadikan acuan dalam pembuatan sistem inforamasi akademik ini. Berdasarkan kebutuhan penelitian ini maka diambil kajian pustaka sesuai dengan kebutuhan pengembangan yang dapat mendukung sistem antara lain tentang sistem informasi penjualan, web dan MySQL yang diambil dari jurnal, buku dan dokumen resmi.

\subsection{Metode Pengembangan Perangkat Lunak}

Metode pengembangan sistem yang digunakan oleh peneliti dalam melakukan penegembagan sistem yaitu metode Waterfall yang sering digunakan dalam proses pengembangan perangkat lunak (RPL), dimana setiap kemajuan dilihat terus mengalir ke bawah (seperti air terjun) melalui tahap, analisis, perancangan, desain, pengkodean dan pengujian, serta implementasi. Dimana metode waterfall (pressman, 2010) ini memiliki beberapa tahapan yang dapat dilihat pada gambar berikut.

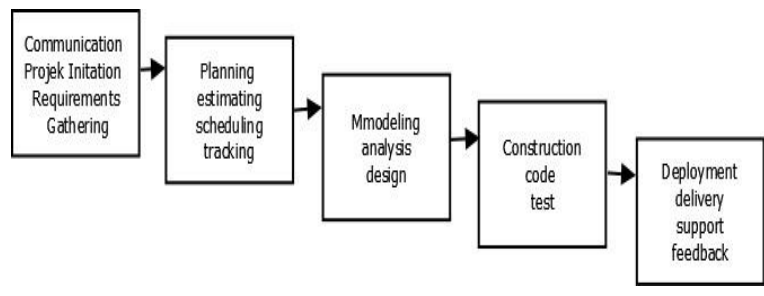

Gambar 3.2 Metode Waterfall.

\section{a) Communication (Projek Initation \& Requirements Gathering)}

Merupakan analisis terhadap aplikasi yang akan dibangun melalui tahapan wawancara atau observasi lansung terhadap objek yang dituju seperti: kebutuhan software, kebutuhan hardware dan tahap untuk melakukan pengumpulan data.

b) Planning (Estimating, Scheduling, Tracking)

Proses perencanaan merupakan lanjutan dari proses analisis. Pada tahap ini dilakukan perencanaan database, pembuatan alur dari hubungan antara komponen dengan sistem menggunakan data flow diagram (DFD) untuk menuntun pembuatan sistem agar tetap sesuai dengan alur yang telah ditentukan.

c) Modeling (Analysis \& design)

Proses ini menerjemahkan sumber daya yang diperlukan dalam membuat sistem. Serta menerjemahkan syarat kebutuhan ke sebuah perancangan software yang dapat diperkirakan sebelum dibuat kode program. Proses ini befokus pada perancangan desain interface aplikasi.

d) Construction (Code \& Test)

Merupakan proses pembuatan kode program yang menerjemahkan desain dalam bahasa yang bisa dikenali oleh computer. Tahapan ini merupakan tahapan secara nyata dalam mengerjakan suatu software.Serta dilakukan pengujian terhadap sistem dan juga kode yang sudah dibuat untuk menemukan kesalahan yang mungkin terjadi untuk nantinya diperbaiki.

e) Deployment (Delivery, Support, Feedback)

Tahapan ini bisa dikatakan selesai dalam pembuatan sebuah sistematau aplikasi.Setelah melakukan analisis, perancangan, desain, maka sistem yang sudah jadi kemudian digunakan oleh $u$ ser dan dilakukan pemeliharaan secara berkala.

\subsection{Waktu Dan Tempat Penelitian}

Berdasarkandari lokasi studi kasus yang dipilih oleh penulis maka waktu dan tempat penelitian adalah sebagai berikut.

a. Waktu penelitian

Waktu yang dibutuhkan dalam penelitian skripsi ini yaitu dari bulan maret sampai dengan bulan juni 2019.

b. Tempat penelitian

Penelitian dilakukan di Pantai Jempol Sumbawa Besar.

\section{PEBAHASAN}

\subsection{Kebutuhan Perangkat Keras}

Berdasarkan dari hasil wawancara dan observasi yang dilakukan di lokasi penelitian maka penulis mendapatkan beberapa data terkait kebutuhan perangkat keras yang digunakan dalam membangun sistem ini yaitu dapat dilihat pada tabel berikut: 
Tabel 4.1 AnalisisKebutuhan Perangkat Keras

\begin{tabular}{|c|l|l|}
\hline No. & \multicolumn{1}{|c|}{ Perangkat } & \multicolumn{1}{|c|}{ Keterangan } \\
\hline 1. & Laptop & ACER \\
\hline 2. & Processor & $\begin{array}{l}\text { Intel }(\text { R) Celeron }(R) \\
\text { @ } 1.40 \text { Ghz }\end{array}$ \\
\hline 3. & Ram & DDR3 2GB \\
\hline 4. & Hardisk & HDD 500GB \\
\hline 5. & VGA & $\begin{array}{l}\text { Intel inside 1366 } \\
768 M b\end{array}$ \\
\hline 6. & Mouse\& Keyboard & Standar \\
\hline
\end{tabular}

\subsection{Kebutuhan Perangkat Lunak}

Berdasarkan hasil wawancara dan observasi yang dilakukan oleh penulis di lokasi penelitian maka perangkat lunak yang dibutuhkan untuk membangun sistem ini yaitu dapat dilihat pada tabel berikut:

Tabel 4.2 Analisis Kebutuhan Perangkat Lunak

\begin{tabular}{|l|l|}
\hline \multicolumn{1}{|c|}{$\begin{array}{c}\text { Perangkat } \\
\text { Lunak }\end{array}$} & \multicolumn{1}{|c|}{ Spesifikasi } \\
\hline $\begin{array}{l}\text { Sistem } \\
\text { operasi }\end{array}$ & Windows 7 \\
\hline Web Browser & Mozila firefox \\
\hline Dreamweaver & Dreamweaver CS 5 \\
\hline Web server & XAMPP versi 7.0.9 \\
\hline $\begin{array}{l}\text { Pengelolah } \\
\text { database }\end{array}$ & PHPMyAdmin \\
\hline $\begin{array}{l}\text { Tools } \\
\text { Pemrograman }\end{array}$ & $\begin{array}{l}\text { a). JavaScript } \\
\text { c). HTML }\end{array}$ \\
\hline Web editor & Sublime Text 3 \\
\hline $\begin{array}{l}\text { Mockups } \\
\text { editor }\end{array}$ & Balsamiq_Mockups_3.5.17 \\
\hline
\end{tabular}

\subsection{Analisis Kebutuhan Data}

Berdasarkan hasil dari analisis peneliti terhadap sistem data yang diperlukan untuk merancang sistem yaitu sebagai berikut diantaranya:
a. Data customer
b. Data produk
c. Dara pesanan
d. Data pembayaran

\subsection{Sistem Yang Berjalan}

Berdasarkan hasil wawancara yang dilakukan penulis pada penjualan kuliner dipantai jempol diketahui sistem yang sedang berjalan pada saat ini seperti pada gambar 4.1 adalah beberapa alur seperti penyimpanan data siswa dan guru.

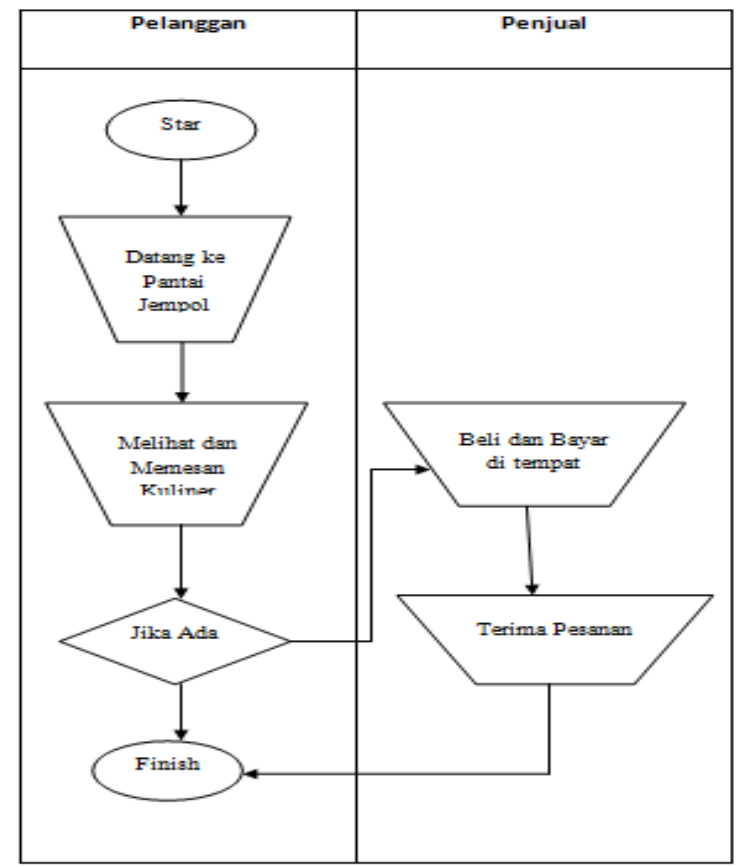

Gambar 4.1 Sistem Yang Sedang Berjalan

Gambar 4.Sistem Yang Sedang Berjalan pada penjualan kuliner dipantai jempolyang terdiri dari data siswa dan data guru pengolahan datanya masih manual dalam proses penyimpanannya.

\subsection{Sistem Yang Diusulkan}

Dari hasil analisa sistem maka dapat disimpulkan hasil rancangan dari aplikasihybrid penjualan kuliner dipantai jempol.

\subsubsection{Gambaran Umum Sistem (Flowmap System)}

Di bagian ini akan digambarkan bagian-bagian dari sistem informasi pengolahan data akademik berbasis web. Yang nantinya akan di akses oleh siswa dan guru. 


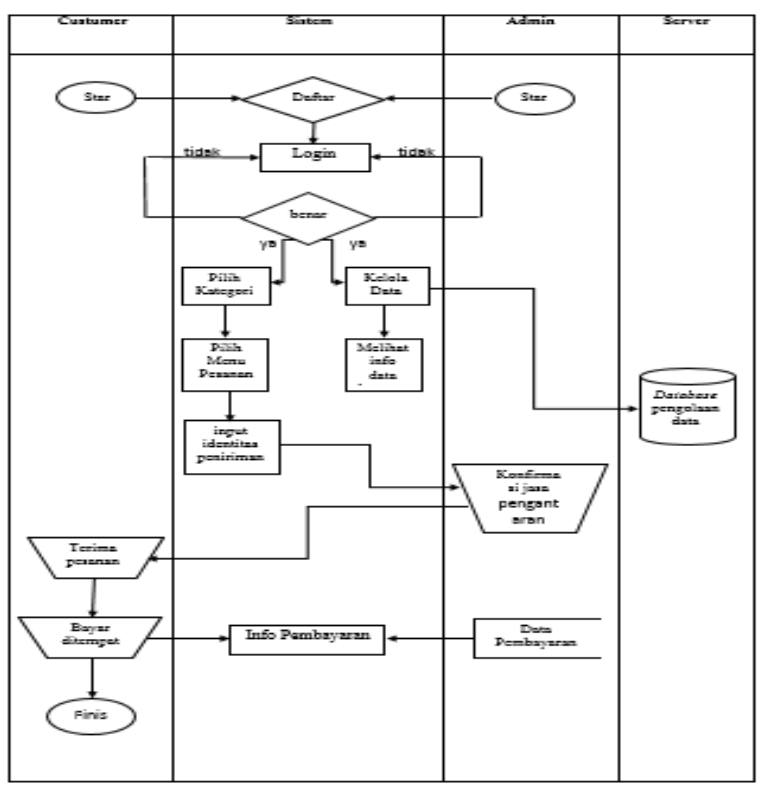

Gambar 4.2 FlowmapSystemyang diusulkan.

\subsection{Rancangan Sistem Usulan}

\subsubsection{Use Case Diagram Admin}

berdasarkan dari sistem yang telah dirancang maka dapat dilihat Use case diagram customerdari sistem yaitu sebagai berikut:

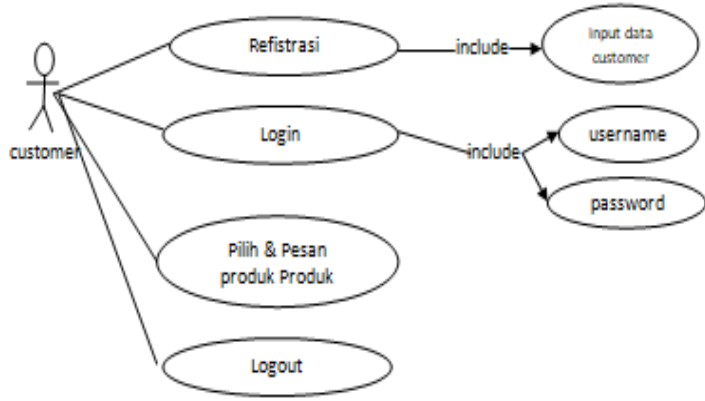

Gambar: 4.3Use Case DiagramCustomer

Pada gambar diatas menjelaskan tentang tahapan alur proses dari customer terhadap aplikasi yang meliputi: Registrasi, Login, Lihat Produk, Pilih dan Pesan Produk dan logout.

\subsubsection{Use Case Diagram Admin}

berdasarkan dari sistem yang telah dirancang maka dapat dilihat Use case diagram admindari sistem yaitu sebagai beriku:

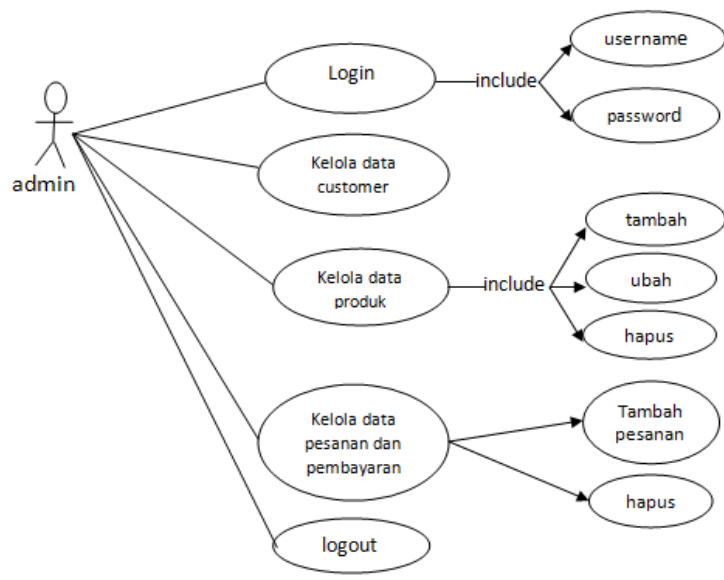

Gambar: 4.4Use Case Diagram Admin

Pada gambar diatas menjelaskan tentang tahapan alur proses dari admin terhadap aplikasi yang meliputi: Login, kelola data customer, kelola data produk, kelola data pesanan dan pembayaran, serta logout.

\subsubsection{ActivityDiagram Admin}

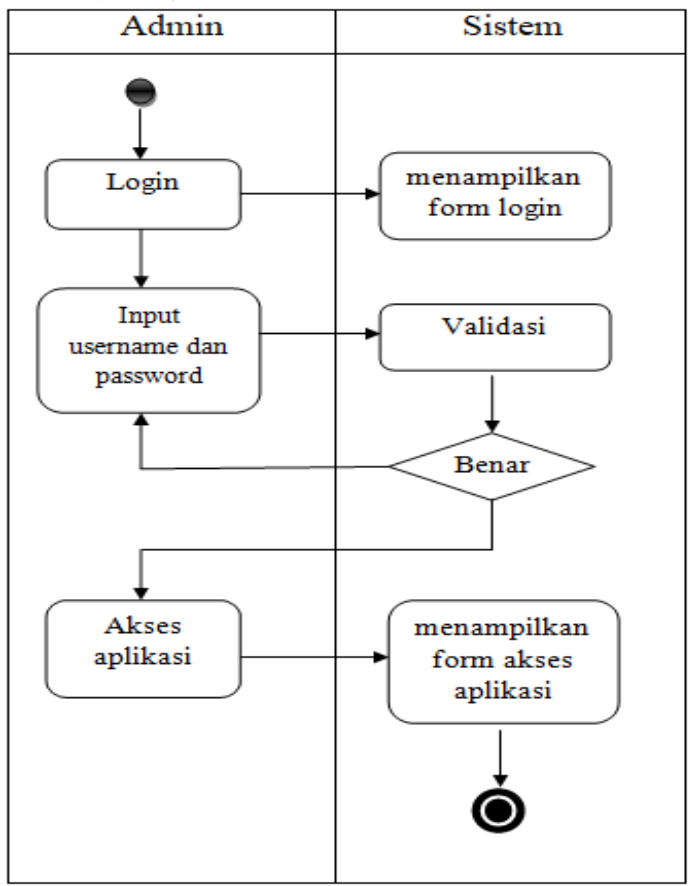

Gambar 4.5 Activity Diagram login admin terhadap aplikasi.

Pada gambar diatas menjelaskan tentang proses dari aktifitas login yang dilakukan oleh admin dalam aplikasi penjualan tersebut. Yang di mualai dari login, validasi username dan pasword (apabila berhasil maka akan lanjuta pada proses selanjutnya). Kemudian setelah masuk maka admin dapat mengakses sistem ditampilkan oleh aplikasi. 


\subsubsection{ActivityDiagram Cutomer}

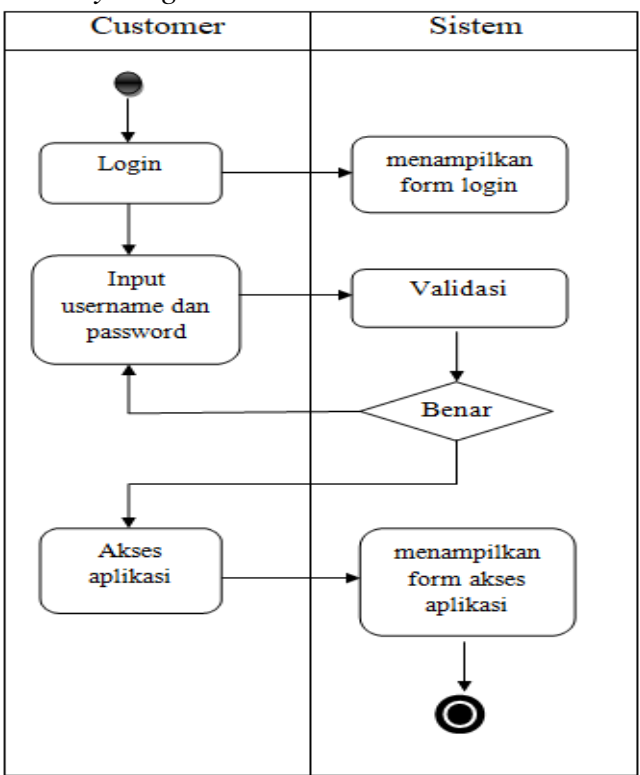

Gambar 4.10 Activity Diagram login customer terhadap aplikasi.

Pada gambar diatas menjelaskan tentang proses dari aktifitas login yang dilakukan oleh customer dalam aplikasi penjualan tersebut. Yang di mualai dari login, validasi username dan pasword (apabila berhasil maka akan lanjuta pada proses selanjutnya). Kemudian setelah masuk maka customer dapat mengakses sistem yang ditampilkan oleh aplikasi.

\subsection{Impelmentasi}

Berdasarkan hasil rancangan user interface dari sistem informasi pengolahan data akademik sekolah maka didapatkan hasil implementasi yaitu sebagai berikut:

\subsubsection{Login Admin}

Berikut implementasi login admin yang terdiri dari beberapa menu yaitu:

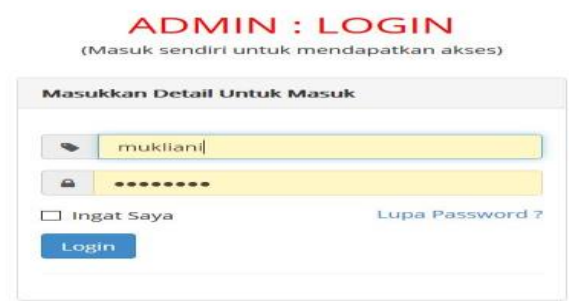

Gambar 4.27 Tampilan Login Admin.
Pada gambar diatas merupakan tampilan dari login yang di proses oleh admin.

\subsubsection{Halaman Utama}

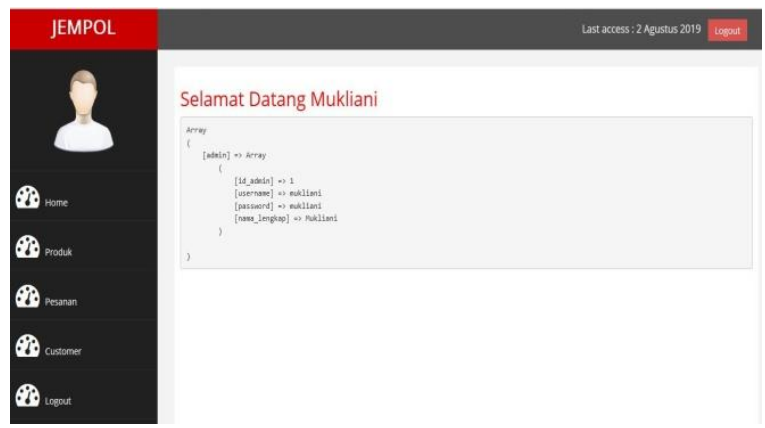

Gambar 4.28 Tampilan Login Admin Sukses.

Pada gambar diatas merupakan tampilan dari sukses login yang di proses oleh admin.

\subsubsection{Tampilan login customer}

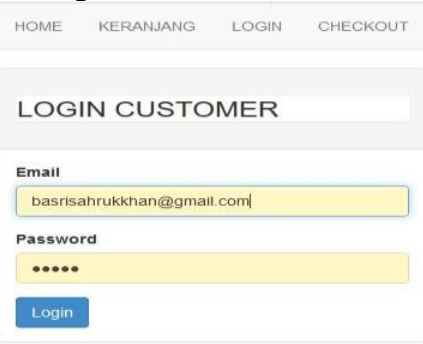

Gambar 4.33 Tampilan Login Customer

Pada gambar diatas merupakan tampilan dari Login yang di proses oleh customer.

\subsubsection{Tampilan Informasi Produk Customer}

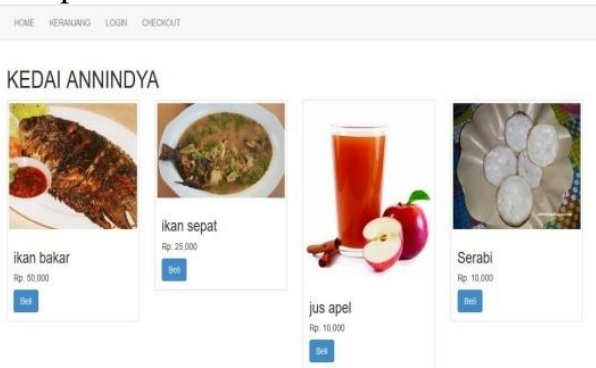

Gambar 4.36 Tampilan Informasi Produk Customer.

Pada gambar diatas merupakan tampilan dari Informasi Produk Customer pada customer. 


\section{KESIMPULAN DAN SARAN}

\subsection{Kesimpulan}

Berdasarkan hasil penelitian yang telah dilakukan maka peneliti menarik sebuah kesimpulan yaitu AplikasiHybrid Penjualan Kuliner Dipantai Jempol Sumbawa telah berhasil dibuat dengan menggunakan metodewaterfall dalam perancangan perangkat lunak, bahasa pemrograman PHP dengan dan MySql sebagai manajemen basis datanya. Dimana pada sistem berupa prototype yang menjadi masukan yang diharapkan dapat membantu dalam pengolahan data serta dapat meningkatkan mutu dan kualitas..

\subsection{Saran}

Adapun saran dan masukan pada sistem yaitu sebagai berikut:

1. Dalam sistem ada baiknya dibuat tampilan yang lebih menarik seperti penambahan untuk mempermudah customer.

2. Melakukan pengembangan pada sistem pengolahan data ini terutama pada pembahasan setiap modul fitur-fitur yang ada agar dapat lebih memudahkan pengguna, admin atau user, seperti melakukan penambahan data.

\section{DAFTAR PUSTAKA}

Abas. "RirihPerancanganAplikasiPengolahan Data ReportPenjualan". JurnalComputech\&Bisnis, Vol. 8, No. 1, Juni 2014, 25-34.
Aditya, Bayu Rima, S.T.,M.T dan Iskandar, Ade Rahmat, S.Kom.,M.T. "Aplikasi Informasi Kegiatan Mahasiswa di Fakultas Ilmu Terapan UniiversitasTelkom Berbasis Android dan SMS Broadcast". e-Proceeding of Applied Science : Vol.1, No.3 Desember 2015

Aryanto, Arip dan TjendrowasonoTri Irianto."Pembangunan SistemPenjualan Online PadaToko Indah Jaya Furniture Surakarta". Journal Speed - Sentra PenelitianEngineering danEdukasi - Volume 4 No 4 - 2012 - ijns.org.

Ihsanuddin, Hidayatullah Drs.Syarif dan Rosmawarni3Neni. "Sistem Informasi Masjid Berbasis Web". Jurnal Rekayasa Informasi, Vol. 5, No.1, April 2016

Mallu,Satriawaty.

"SistemPendukungKeputusanPenentuanKaryaw anKontrakMenjadiKaryawanTetapMenggunaka nMetodeTopsis".

JurnalIlmiahTeknologiInformasiTerapan

Volume I, No 2, 30 April 2015.

Pamungkas,

GilangdanYuliansyahHerman."RancangBangun

Aplikasi Android Pos (Point Of Sale) KafeUntukKasir Portable Dan Bluetooth Printer". JurnalSainsdanTeknologi, Vol. 6, No. 1, April 2017.

Wahana, Agung dan RiswayaAsepRirih. "RirihPerancanganAplikasiPengolahan Data ReportPenjualan". JurnalComputech\&Bisnis, Vol. 8, No. 1, Juni 2014, 25-34. 